\title{
FAKTOR RISIKO ANEMIA IBU HAMIL TERHADAP PANJANG BADAN LAHIR PENDEK DI PUSKESMAS SENTOLO 1 KULON PROGO D.I.YOGYAKARTA
}

\author{
Risk Factors of Anemia Status among Pegnant Woman on Stunted Birth Length in Puskesmas \\ Sentolo 1, Kulon Progo D.I. Yogyakarta \\ Rolla Destarina \\ Lembaga Penelitian dan Pengembangan 'Aisyiyah Pimpinan Wilayah 'Aisyiyah D.I. Yogyakarta \\ E-mail: rolla.destarina@gmail.com
}

\begin{abstract}
Anemia is a condition in which the hemoglobin $(\mathrm{Hb})$ level in the blood is below normal. $\mathrm{Hb}$ plays an important role in transporting oxygen through the body. If the mother is anemic, the oxygen cycle in the body is reduced and will result in the increased of metabolic rate during pregnancy. Anemia during pregnancy will increase risk factors in inhibiting growth and low birth weight (LBW), premature birth, infant mortality, perinatal death and reduce body defenses to infection either in mother and child. This study aimed to determine the anemia status of pregnancy is a risk factor for producing stunting at birth in Puskesmas Sentolo 1 Kulon Progo. The sample of 192 babies were employed, 64 babies with short birth lenght for case group and control group covered 128 babies with normal birth lenght. Data obtained through data from Puskesmas medical record in 2016 then analyzed by using the case-control approach. The independent variable is the anemia status of pregnant mother while the dependent variabel is the length of birth. The data were analysed by using Chi-Square test to find out the correlation between of maternal anemia status with short birth lenght, then to identify risk factor using Odd-Ratio. The result of the study indicated that there was a relationship between anemia status of pregnant woman and shortstature at birth marked by $p$-value $=0,000(p<0.05)$. In addition, the anemia status of pregnant woman is a risk factor for short body length at birth $(\mathrm{OR}=4.31 ; 95 \% \mathrm{Cl}=2.28-8.15)$. Conclusion, anemia status of pregnant woman is a risk factor for stunting at birth in Puskesmas Sentolo 1 Kulon Progo.
\end{abstract}

Keywords: anemia, pregnant woman, length at birth, stunting

\section{ABSTRAK}

Anemia adalah kondisi dimana kadar hemoglobin $(\mathrm{Hb})$ dalam darah dibawah normal. $\mathrm{Hb}$ berperan didalam pengangkutan Oksigen ke seluruh tubuh. Jika lbu mengalami anemia, maka siklus Oksigen di dalam tubuh berkurang dan akan mengakibatkan teganggunya metabolisme yang meningkat selama proses kehamilan. Anemia selama masa kehamilan akan meningkatkan faktor risiko dalam menghambat pertumbuhan dan berat badan lahir rendah (BBLR), kelahiran prematur, kematian bayi dalam kandungan, kematian perinatal dan pertahanan tubuh berkurang yang mengakibatkan infeksi terhadap ibu dan anaknya. Penelitian ini betujuan untuk mengetahui status anemia ibu hamil merupakan faktor risiko terhadap panjang badan lahir pendek di Puskesmas Sentolo 1 Kulon Progo. Sampel yang digunakan berjumlah 192 bayi dengan kelompok kasus sebanyak 64 bayi dengan panjang badan lahir pendek dan kelompok kontrol sejumlah 128 dengan panjang badan lahir normal. Data diperoleh dengan menyalin dari rekam medis Puskesmas tahun 2016 kemudian dianalisa menggunakan pendekatan case control. Variabel bebas adalah status anemia ibu hamil sedangkan variabel terikat adalah panjang badan lahir. Pengolahan data menggunakan uji Chi-Square untuk mengetahui adanya hubungan antara status anemia ibu hamil dengan panjang badan lahir, kemudian untuk mengidentifikasi faktor risiko menggunakan Odd-Ratio. Hasil penelitian ini menunjukkan bahwa ada hubungan antara status anemia ibu hamil dengan panjang badan lahir pendek ditandai dengan nilai $p$ value $=0,000(p<0,05)$. Selain itu, status anemia ibu hamil menjadi faktor risiko panjang badan lahir pendek (OR=4,31;95\% Cl=2,28 - 8,15). Kesimpulan dari penelitian bahwa status anemia ibu hamil menjadi faktor risiko panjang badan lahir pendek di Puskesmas Sentolo 1 Kulon Progo.

Kata kunci: anemia, ibu hamil, panjang badan lahir, stunting 


\section{PENDAHULUAN}

A nemia merupakan kondisi yang ditandai dengan penurunan abnormal masa total sel darah merah. ${ }^{1}$ Penyebabnya terdiri dari tiga faktor terpenting yaitu kehilangan darah karena pendarahan akut atau kronis, pengrusakan sel darah merah, dan produksi sel darah merah yang tidak cukup banyak. ${ }^{2}$

Pada tahun 2011, WHO mencatat bahwa anemia merupakan masalah kesehatan yang ekstrem di seluruh dunia dengan persentase mencapai 37 persen, yang sebagian besarnya terjadi pada masyarakat di negara-negara berkembang seperti Asia Tenggara dan Afrika. ${ }^{3}$ Sementara di Indonesia, prevalensi anemia gizi besi mencapai 25,2 persen. Prevalensi anak balita sebesar 28,1 persen, anak 5-12 tahun sebesar 29 persen, serta remaja putri dan wanita usia subur 13-49 tahun masing-masing sebesar 22,7 persen. Keadaan ini menunjukkan bahwa anemia merupakan masalah kesehatan masyarakat yang masih membutuhkan perhatian. Sedangkan salah satu kelompok yang berisiko tinggi mengalami anemia adalah ibu hamil yang proporsinya mencapai 37,1 persen. Angka tersebut sudah mendekati masalah kesehatan masyarakat berat (severe public health problem) yang batas prevalensinya $\geq 40$ persen. ${ }^{4}$ Dalam konteks penelitian ini, yang mengambil lokasi di Puskesmas Sentolo 1 Kulon Progo, D.I. Yogyakarta, jumlah anemia ibu hamil mencapai 29,26 persen berdasarkan profil Puskesmas Sentolo 1 Kulonpogo pada tahun 2016. Sehingga membutuhkan intervensi guna mencegah angka prevalensinya tidak bertambah.

Anemia dapat menyebabkan dampak serius seperti menimbulkan kelelahan, badan lemah, penurunan kapasitas/kemampuan atau produktifitas kerja bagi penderitanya. Konsekuensi lainnya yaitu penurunan imunitas, kinerja yang terbatas dan berkurangnya fungsi kognitif pada anak usia sekolah, sementara itu juga akan bedampak pada kesejahteraan generasi berikutnya dengan mempengaruhi hasil kelahiran, pertumbuhan dan perkembangan anak. ${ }^{5}$

Penelitian ini mengambil fokus pada anemia ibu hamil, oleh karena itu keberhasilan pada kehamilan sangat ditentukan oleh salah satunya kecukupan gizi, baik itu gizi makro atau gizi mikro. Sehingga ibu hamil membutuhkan konsumsi energi dan zat-zat gizi yang adekuat untuk menopang pertumbuhan dan kesehatan janin dan dirinya sendiri. ${ }^{6}$ Salah satu pemenuhan zat gizi yang diperlukan oleh ibu hamil adalah pemenuhan tambahan zat besi karena faktor peningkatan volume darah ibu semasa kehamilan. ${ }^{7}$

Anemia pada ibu hamil sendiri terjadi karena volume darah ibu yang meningkat hingga kurang lebih 150 persen dari normal, namun sel darah merah hanya meningkat sebesar 20-30 persen. Peningkatan tersebut dikarenakan untuk menunjang pemenuhan kebutuhan janin. Hal ini berakibat rasio sel darah merah terhadap volume darah menurun. Pengenceran darah selama kehamilan ini kemudian dikenal sebagai anemia faali. ${ }^{6}$

Ibu hamil yang mengalami anemia pada derajat ringan memang tidak berakibat fatal, namun pada derajat sedang atau bahkan pada derajat berat anemia akan berpengaruh serius tehadap proses kehamilan, persalinan, nifas, serta menyebabkan morbiditas dan mortalitas anak dan ibu meningkat. ${ }^{8}$ Anemia memiliki konsekuensi gizi dan kesehatan yang berpengaruh terhadap pertumbuhan dan perkembangan mental pada anak. Anemia selama masa kehamilan meningkatkan faktor risiko dalam menghambat pertumbuhan dan berat badan lahir rendah (BBLR), kelahiran prematur, kematian bayi dalam kandungan, kematian perinatal dan pertahanan tubuh berkurang yang mengakibatkan infeksi terhadap ibu dan anaknya. ${ }^{9}$

Angka kejadian anemia pada ibu hamil di Indonesia tergolong tinggi, oleh karena itu penelitian ini mengambil lokasi di Puskesmas Sentolo 1, Kulon Progo D.I. Yogyakarta. Wilayah ini ditemukan kasus gizi masyarakat salah satunya yaitu ibu hamil yang mengalami anemia yaitu sekitar 29,26 persen. Situasi ini ditopang oleh profil kesehatan di Puskesmas Sentolo 1 tahun 2016 yang menunjukkan 17 persen bayi lahir memiliki panjang badan kurang dari $48 \mathrm{~cm}$. Oleh karenanya, penelitian ini ingin mengangkat pengaruh masalah status anemia pada ibu hamil terhadap panjang badan bayi lahir. Penelitian ini bertujuan untuk mengetahui mengenai faktor risiko anemia ibu hamil terhadap panjang badan lahir pendek di Puskesmas Sentolo 1 Kulon Progo D.I.Yogyakarta. 


\section{METODE PENELITIAN}

Penelitian yang dilakukan ini merupakan penelitian epidemiologi dengan rancangan penelitian analitik case control. Istilah case dan control menunjukan bahwa, setiap kasus yaitu panjang badan lahir pendek, yang dicarikan kontrolnya yaitu panjang badan lahir normal. Penelitian ini memanfaatkan data sekunder dari data rekam medis tahun 2016 di Puskesmas Sentolo 1, Kulon Progo, D.I. Yogyakarta .

Populasi dalam penelitian adalah semua bayi yang lahir dan terdaftar di Puskesmas Sentolo 1, Kulon Progo, D.I. Yogyakarta pada tahun 2016, dengan jumlah 315 bayi lahir. Sampel penelitian diambil dengan cara menghitung jumlah kasus dan kontrol. Kriteria Inklusi sampel yang digunakan dalam penelitian ini adalah bayi yang lahir dan memiliki catatan rekam medis lengkap di Puskesmas Sentolo 1 Kulon Progo, bayi lahir cukup bulan, dan bayi yang lahir dalam keadaan sehat tanpa penyakit penyerta. Dari kriteria tersebut didapatkan kelompok kasus yaitu bayi dengan panjang badan pendek (stunted) sebanyak 64 kasus dengan kriteria lahir kurang dari $48 \mathrm{~cm}$. Kedua, kelompok kontrol yaitu bayi dengan panjang badan normal sebanyak 128 bayi dengan kriteria panjang lahir lebih besar atau sama dengan $48 \mathrm{~cm}$ dan jenis kelamin bayi dilakukan matching dengan kelompok kasus. Variabel bebas dalam penelitian ini adalah status anemia ibu hamil yang diukur dengan metode cyanmethemoglobin yang dinyatakan dalam $\mathrm{g} / \mathrm{dl}$ dan variabel terikat adalah panjang badan lahir yang diukur menggunakan pengukur panjang badan bayi (length board) merk infantometer dengan tingkat ketelitian $0,1 \mathrm{~cm} / 1 \mathrm{~mm}$. Cara pengumpulan data yaitu dengan cara menyalin dari data rekam medis dari bulan Januari sampai Desember 2016 di Puskesmas Sentolo 1 Kulon Progo.

Penelitian ini menggunakan analisis univariat dengan tujuan menganalisis deskriptif variabel penelitian. Analisis univariat digunakan untuk mengestimasi parameter populasi yaitu karakteristik ibu hamil diantaranya yaitu usia yang dikategorikan menjadi empat rentan usia 20-25 tahun, 26-30 tahun, 32-35 tahun dan 3640; status pekerjaan ibu hamil yang dibagi menjadi 2 kategori yaitu ibu hamil yang bekerja dan ibu hamil yang tidak bekerja. Selain itu, status gizi bayi lahir yang terdiri dari berat badan lahir normal dan BBLR; serta panjang badan lahir normal dan stunted. Kedua karakteistik tersebut disajikan dalam data kategorik dengan ukuran distribusi frekuensi dan presentase dari tiap variabel. Analisis bivariat berfungsi untuk mengetahui besarnya faktor risiko status anemia ibu hamil terhadap panjang badan lahir pendek dengan menggunakan Odds Ratio. Selain itu, untuk mengetahui hubungan antara status anemia ibu hamil dengan panjang badan lahir bayi menggunakan uji Chi-Square. Uji statistik ini menggunakan software komputer SPSS.

\section{HASIL}

Data di Puskesmas Sentolo 1 Kulon Progo pada tahun 2016 mengenai usia ibu hamil dikategorikan dengan rentang usia usia 20-25 tahun, 26-30 tahun, 32-35 tahun, dan 36-40 tahun. Persentase tertinggi ada pada rentang usia 26-30 tahun yakni sebesar 37 persen dengan jumlah 116 ibu hamil. Sedangkan usia 20-25 tahun yang merupakan kategori usia ibu hamil termuda sebanyak 35 persen dengan jumlah 111 ibu hamil. Beranjak ke rentang usia 32-35 tahun, terdapat 26 persen ibu hamil atau sama dengan 81 orang ibu hamil, dan usia 3640 persen sebagai persentase terendah dengan 7 ibu hamil atau 2 persen dari total ibu hamil yang telah didata pada tahun 2016.

Usia ibu hamil (maternal age) sebaiknya tidak terlalu muda dan tidak terlalu tua. Usia yang kurang dari 20 tahun atau lebih dari 35 tahun, berisiko tinggi untuk melahirkan. Manuaba mencatat bahwa kehamilan di bawah usia 20 tahun memiliki risiko anemia, ganggungan tumbuh kembang janin, keguguran, prematuritas, atau BBLR, gangguan persalinan, preeklampsi, perdarahan antepartum. ${ }^{10}$ Sementara Murphy menulis bahwa risiko keguguran spontan akan meningkat dengan bertambahnya usia terutama setelah usia 30 tahun, baik kromosom janin itu normal atau tidak. Ibu hamil dengan usia lebih tua, lebih besar kemungkinan keguguran baik janinnya normal atau abnormal. ${ }^{11}$

Jika merujuk pada perspektif Padila, usia ibu saat melahirkan merupakan salah satu faktor risiko kematian perinatal. Dalam kurun waktu reproduksi sehat diketahui bahwa usia aman untuk persalinan adalah 20-35 tahun. ${ }^{12}$ Oleh karena itu, persentase ibu hamil di wilayah 
kerja Puskesmas Sentolo 1, Kulon Progo tergolong dalam aman untuk persalinan.

Sementara ibu hamil yang bekerja yaitu sebanyak 24 persen atau 75 ibu dan ibu hamil tidak bekerja sebanyak 76 persen atau ada 240 ibu. Ibu hamil yang tidak bekerja lebih banyak dari pada ibu hamil yang bekerja. Dalam konteks ini, Dunifon dan Gill melakukan studi yang menemukan bahwa ibu hamil yang bekerja telah meningkat tajam dalam beberapa dekade terakhir. Mereka juga mencatat bahwa beberapa ibu hamil bekerja dalam pekerjaan yang tidak stabil, di luar jam standar, atau memerlukan perjalanan yang panjang ke tempat kerja. Keadaan ini disebabkan karena kebutuhan dan pilihan. Di sisi lain tentunya faktor ekonomi sehingga menuntut sebagian ibu hamil harus bekerja. ${ }^{13}$

Arisman mengatakan bahwa bekerja dan tidak bekerja bukan menjadi faktor yang menimbulkan masalah pada ibu hamil, melainkan aktivitas bekerja yang berlebih, dan kurangnya istirahatlah yang memberi pengaruh pada ibu hamil khususnya pada kekurangan zat besi. $^{14}$
Dalam hal tingkat pendidikan, ibu hamil yang berpendidikan jenjang Sekolah Menengah Atas (SMA) sebanyak 80 persen atau 253 ibu hamil. Di urutan kedua terdapat 12 persen ibu hamil berpendidikan Sekolah Menengah Pertama (SMP) dengan jumlah 39 ibu hamil. Sementara ibu hamil yang berpendidikan hingga Perguruan Tinggi (PT) sebanyak 5 persen atau 15 orang ibu hamil, dan yang berpendidikan Sekolah Dasar (SD) sebanyak 3 persen atau hanya 8 ibu hamil.

Tingkat pendidikan kerap memberi dampak pada kurangnya pengetahuan tentang kehamilan. Akibat dari rendahnya pengetahuan dari ibu hamil tidak jarang kehamilan banyak menimbulkan kematian baik pada ibu maupun pada bayi yang dilahirkan atau bahkan keduaduanya. Tingkat pendidikan dari ibu yang rendah juga dapat menyebabkan kurangnya pengetahuan ibu tentang kesehatan termasuk di dalamnya tentang pentingnya pemeriksaan kehamilan. ${ }^{15}$ Sejalan dengan Zimmerman, Woolf, dan Haley, tingkat pendidikan dan kesehatan memiliki hubungan yang menguntungkan dan mempengaruhi untuk mendapatkan hasil kesehatan yang lebih baik. ${ }^{16}$

Tabel 1

Karakteristik Ibu Hamil

\begin{tabular}{ccc}
\hline Variabel & Frekuensi (orang) & Persentase $(\%)$ \\
\hline Usia (tahun) & 111 & 35 \\
$20-25$ & 116 & 37 \\
$26-30$ & 81 & 26 \\
$32-35$ & 7 & 2 \\
$36-40$ & & \\
Status Pekerjaan & 75 & 24 \\
Bekerja & 240 & 76 \\
Tidak Bekerja & & \\
Pendidikan & 8 & 3 \\
SD & 39 & 12 \\
SMP & 253 & 80 \\
SMA & 15 & 5 \\
PT & &
\end{tabular}

Tabel 2

Status Anemia Ibu Hamil

\begin{tabular}{lcc}
\hline Variabel & Frekuensi (orang) & Persentase (\%) \\
\hline Status Anemia & & \\
Anemia & 96 & 30 \\
Tidak Anemia & 219 & 70 \\
\hline
\end{tabular}


Penelitian ini mengkategorikan status anemia ibu hamil menjadi dua yaitu ibu hamil anemia dan ibu hamil tidak anemia. Data diperoleh dari data rekam medis di Puskesmas Sentolo 1 Kulon Progo pada tahun 2016.

Bedasarkan Tabel 2 dapat diketahui bahwa ibu hamil yang mengalami anemia di Puskesmas Sentolo 1 ada sebanyak 30 persen atau ada 96 ibu hamil. Sedangkan yang ibu yang tidak anemia berjumlah $219(70 \%)$ ibu hamil. Anemia pada ibu hamil terjadi karena volume darah ibu yang meningkat hingga kurang lebih 150 persen dari normal namun sel darah merah hanya meningkat sebesar 20-30 persen. Peningkatan tersebut dikarenakan untuk menunjang pemenuhan kebutuhan janin. Hal tesebut berakibat rasio sel darah merah terhadap volume darah menurun. Pengenceran darah selama kehamilan ini dikenal sebagai anemia faali. ${ }^{6}$

Anemia defisiensi besi pada ibu hamil terjadi karena asupan zat besi yang kurang dan penyerapan zat besi yang meningkat pada ibu sehingga menyebabkan produksi eritrosit menurun dan menipisnya cadangan zat besi di dalam tubuh. ${ }^{17}$ Sementara hemoglobin merupakan senyawa yang membawa oksigen pada sel darah merah, dan digunakan secara luas untuk menetapkan prevalensi anemia.
Metode yang digunakan untuk mengukur hemoglobin secara kimia dengan menggunakan metode Sahli untuk membandingkan senyawa akhir secara visual terhadap standar gelas warna. Metode tersebut merupakan metode paling sederhana dan banyak digunakan, sedangkan metode yang lebih canggih adalah metode cyanmethemoglobin. ${ }^{18}$

Secara umum, berat badan bayi lahir dipahami sebagai keadaan fisik bayi lahir yang diukur menggunakan timbangan baby scale. Tabel 3 menjelaskan mengenai status gizi bayi lahir yang meliputi berat badan dan panjang badan lahir di Puskesmas Sentolo 1 Kulon Progo pada tahun 2016. Berat badan bayi pada penelitian ini dibagi menjadi dua ketegori yaitu berat badan lahir normal dan berat badan lahir rendah (BBLR).

Data tersebut menunjukkan bahwa mayoritas bayi lahir normal di Puskesmas Sentolo 1, Kabupaten Kulon Progo dengan 90 persen atau sebanyak 284 bayi. Sementara 10 persen bayi lahir dengan Berat Badan Lahir Rendah (BBLR) atau sebanyak 31 bayi. Beberapa faktor yang menyebabkan berat badan lahir rendah sebagaimana hasil studi Suryati yakni penambahan berat badan ibu saat hamil, anemia ibu hamil, kekurangan energi kronik (KEK), dan jarak kehamilan. ${ }^{19}$

Tabel 3

Staus Gizi Bayi Lahir

\begin{tabular}{lcc}
\hline Variabel & Frekuensi (orang) & Persentase (\%) \\
\hline Berat Badan Lahir & 284 & 90 \\
$\quad$ Normal & 31 & 10 \\
$\quad$ BBLR & & \\
Panjang Badan Lahir & 251 & 80 \\
$\quad$ Normal & 64 & 20 \\
$\quad$ Stunted/Pendek &
\end{tabular}

Tabel 4

Status Panjang Badan Lahir berdasarkan Jenis Kelamin Bayi

\begin{tabular}{lcccccc}
\hline & \multicolumn{7}{c}{ Panjang Badan Lahir } \\
\cline { 2 - 7 } Jenis Kelamin & \multicolumn{2}{c}{ Normal } & \multicolumn{2}{c}{ Stunted } & \multicolumn{2}{c}{ Total } \\
\cline { 2 - 7 } & $\mathrm{n}$ & $\%$ & $\mathrm{n}$ & $\%$ & $\mathrm{n}$ & $\%$ \\
\hline Laki-Laki & 56 & 44 & 28 & 44 & 84 & 44 \\
Perempuan & 72 & 56 & 36 & 56 & 108 & 56 \\
\hline Total & 128 & 100 & 64 & 100 & 192 & 100 \\
\hline
\end{tabular}


Keadaan fisik bayi baru lahir diukur dari ujung kepala sampai ujung kaki dalam keadaan terlentang dan diukur menggunakan pengukur panjang badan bayi (length board). Panjang badan bayi lahir dikategorikan menjadi dua yaitu panjang badan lahir normal dan panjang badan lahir pendek (Stunted).

Data status gizi bayi lahir berdasarkan panjang badan lahir menujukan sebanyak 20 persen bayi memiliki panjang badan pendek (stunted) yaitu sebanyak 64 bayi. Sedangkan 80 persen bayi memiliki panjang badan normal atau sebanyak 251 bayi. Banyak faktor yang mempengaruhi tumbuh kembang janin dalam kandungan. Secara umum faktor biologik, risiko lingkungan sosial, dan ada tidaknya faktor protektif mempengaruhi kualitas bayi sewaktu lahir. ${ }^{20}$ Oleh karena itu, ibu hamil diharapkan memperhatikan gizi maternal kerena makanan yang benar akan berdampak baik untuk pertumbuhan janin yang dikandungnya. ${ }^{20}$

Sampel pada penelitian ini berjumlah 192 bayi yang lahir di Puskesmas Sentolo 1, Kulon Progo. Sampel penelitian terdiri dari 64 bayi kelompok kasus (Panjang Badan Lahir Stunted) dan 128 bayi kelompok kontrol (Panjang Badan Lahir Normal). Sampel dilakukan matching dengan menyamakan jenis kelamin antara kelompok kasus dan kelompok kontrol.

Melihat dari penjabaran Tabel 4, dapat diketahui bahwa dari 192 bayi lahir dengan jenis kelamin laki-laki ada sebanyak 84 bayi (44\%) dan yang lahir dengan jenis kelamin perempuan ada 108 bayi (56\%). Bayi laki-laki yang memiliki panjang badan lahir kurang dari $48 \mathrm{~cm}$ (stunted) sebanyak 28 bayi, sedangkan bayi perempuan yang memiliki panjang badan pendek ada sebanyak 36 bayi.
Pada penelitian ini, panjang badan bayi lahir dikelompokan menjadi dua kategori yaitu panjang badan lahir normal (jika lebih $\geq 48 \mathrm{~cm}$ ) dan panjang badan lahir pendek (stunted) jika < $48 \mathrm{~cm}$. Sedangkan untuk status anemia ibu hamil dikelompokan menjadi dua kategori yaitu anemia jika kadar $\mathrm{Hb}$ ibu saat hamil $<11 \mathrm{~g} / \mathrm{dL}$ dan tidak anemia jika kadar $\mathrm{Hb}$ ibu saat hamil $\geq 11 \mathrm{~g} / \mathrm{dL}$. Status anemia ibu hamil sebagai faktor risiko panjang badan lahir pendek dapat dilihat pada Tabel 5.

Berdasarkan Tabel 5 diketahui bahwa dari 192 bayi lahir, ibu yang mengalami anemia dan bayi dengan panjang badan lahir pendek ada sebanyak 61 persen. Sedangkan ibu hamil yang tidak mengalami anemia dan bayi dengan panjang badan lahir pendek namun ada sebanyak 39 persen. Ibu mengalami anemia namun bayi lahir dengan panjang badan lahir normal namun ada sebanyak 27 persen. Sedangkan ibu tidak mengalami anemia dan bayi dengan panjang badan normal ada sebanyak 73 persen.

Hasil analisis Chi Square menyatakan bahwa ada hubungan yang signifikan antara keadaan anemia ibu hamil dengan panjang badan lahir pendek ditandai dengan nilai $p$ value $=0,000 \quad(p<0,05) . \quad$ Pada inteval kepercayaan (Cl) $95 \%$, nilai Odds Ratio (OR) yang dihitung $(4,13)$ masih berada pada rentang atas dan bawah $(\mathrm{Cl}=2,28-8,15)$. Nilai Odds Ratio menunjukan bahwa ibu hamil anemia lebih berisiko 4,31 kali lebih besar melahirkan bayi dengan panjang badan pendek (stunted) daripada ibu hamil yang tidak anemia. Hasil dari hasil analisis tesebut dapat dinyatakan bahwa anemia merukapan faktor risiko terhadap kejadian panjang badan lahir pendek atau hipotesis dapat diterima.

Tabel 5

Status Anemia tehadap Panjang Badan Lahir Pendek

( $n=192$ bayi)

\begin{tabular}{|c|c|c|c|c|c|c|c|c|}
\hline \multirow{3}{*}{$\begin{array}{l}\text { Status Anemia Ibu } \\
\text { Hamil }\end{array}$} & \multicolumn{4}{|c|}{ Panjang Badan Lahir } & & & \multirow{3}{*}{$\begin{array}{c}\text { OR } \\
(95 \% \mathrm{Cl})\end{array}$} & \multirow{3}{*}{$p$} \\
\hline & \multicolumn{2}{|c|}{ Stunted } & \multicolumn{2}{|c|}{ Normal } & \multicolumn{2}{|c|}{ Total } & & \\
\hline & $\mathrm{n}$ & $\%$ & $n$ & $\%$ & $n$ & $\%$ & & \\
\hline Anemia & 39 & 61,0 & 34 & 27,0 & 73 & 38,0 & 4,31 & \\
\hline Tidak Anemia & 25 & 39,0 & 94 & 73,0 & 119 & 62,0 & $(2,28-8,15)$ & 0,00 \\
\hline Total & 64 & 100 & 128 & 100 & 192 & 100 & & \\
\hline
\end{tabular}




\section{BAHASAN}

Populasi pada penelitian ini yaitu berjumlah 315 bayi lahir yang ada di Puskesmas Sentolo 1 pada tahun 2016. Sedangkan sampel penelitian yang digunakan berjumlah 192 bayi yang lahir di Puskesmas Sentolo 1, Kulon Progo. Sampel penelitian terdiri dari 64 bayi kelompok kasus (Panjang Badan Lahir Stunted) dan 128 bayi kelompok kontrol (Panjang Badan Lahir Normal). Sampel dilakukan matching dengan menyamakan jenis kelamin antara kelompok kasus dan kelompok kontrol. Bayi laki-laki memiliki panjang badan lahir kurang dari $48 \mathrm{~cm}$ (stunted) ada $43 \%$ atau sebanyak 28 bayi, sedangkan bayi perempuan yang memiliki panjang badan pendek ada 56 persen atau sebanyak 36 bayi. Pada penelitian ini diketahui bahwa 192 bayi lahir dengan panjang badan pendek dan dengan ibu yang mengalami anemia ada sebanyak 61 persen. Sedangkan bayi dengan panjang badan lahir pendek namun ibu tidak mengalami anemia ada sebanyak 39 persen. Bayi lahir dengan panjang badan lahir normal namun ibu mengalami anemia ada sebanyak 27 persen. Sedangkan bayi dengan panjang badan normal dan ibu tidak mengalami anemia ada sebanyak 73 persen.

Hasil analisis Chi Square menyatakan bahwa ada hubungan yang signifikan antara keadaan anemia ibu hamil dengan panjang badan lahir pendek ditandai dengan nilai $p$ value $=0,000(p<0,05)$. Pada inteval kepercayaan (Cl) $95 \%$, nilai Odds Ratio (OR) yang dihitung $(4,13)$ masih berada pada rentang atas dan bawah $(\mathrm{Cl}=2,28-8,15)$. Nilai Odds Ratio menunjukan bahwa ibu hamil anemia lebih berisiko 4,31 kali lebih besar melahirkan bayi dengan panjang badan pendek (stunted) daripada ibu hamil yang tidak anemia. Hasil analisis tesebut dapat dinyatakan bahwa anemia merukapan faktor risiko terhadap kejadian panjang badan lahir pendek atau hipotesis dapat diterima.

Hal ini sejalan dengan hasil penelitian yang dilakukan oleh Gaur, Kataria, dan Agarwal mencatat bahwa anemia pada ibu sangat mempengaruhi berat badan bayi pada saat lahir rendah. Pada analisis multivariat dengan uji ANOVA, anemia ibu sangat signifikan berpengaruh pada berat bayi, lingkar dada dan lengan, dan juga signifikan tehadap panjang badan bayi dan lingkar betis bayi neonatus. ${ }^{21}$
Anemia adalah kondisi yang bercirikan penurunan secara abnormal pada seluruh bagian sel darah merah. ${ }^{1}$ Anemia disebabkan oleh 3 faktor terpenting yaitu kehilangan darah karena pendarahan akut atau kronis, pengrusakan sel darah merah, dan produksi sel darah merah yang tidak cukup banyak. ${ }^{2}$ Beberapa tanda dan gejala dari anemia defisiensi zat besi $(\mathrm{Fe})$ adalah kehilangan nafsu makan, kelelahan, gangguan kapasitas fungsional (penurunan produksi ATP), sulit berkonsentrasi, sensitifitas terhadap dingin, bernafas cepat saat melakukan aktifitas. Selain itu, kulit kering dan pucat, rambut mudah rontok, kuku berbentuk sendok dan rapuh. Tanda lainnya bisa diketahui dengan memperhatikan sistem kardiovaskular yaitu dispnea eksertional, denyut jantung cepat, palpitasi, dan mudah pusing. Terjadinya penurunan sistem imun sehingga mudah terkena infeksi dan rentan terhadap malaria. Sedangkan gejala pada anakanak dapat dilihat adanya gangguan pertumbuhan dan gangguan perkembangan intelektual. 22

lbu hamil yang mengalami anemia gizi besi rentan terhadap kelahiran prematur dan berat badan bayi lahir kurang. Hal ini karena selama kehamilan dibutuhkan peningkatan produksi eritrosit yang komposisinya relatif pada lingkungan hypoxintrauterine dan suplai oksigen ke janin yang dibutuhkan untuk perkembangan. Zat besi yang adekuat dibutuhkan pada perjalanan melintasi plasenta untuk memastikan kelahiran sesuai dengan usia kehamilan penuh. Selain itu, zat besi juga dibutuhkan untuk pertumbuhan postnatal pada peningkatan sel darah merah dan sebagai unsur pembangun masa tubuh bayi. ${ }^{23}$

Beberapa penyebab utama stunting diantaranya adalah hambatan pertumbuhan dalam kandungan, asupan zat gizi yang tidak mencukupi untuk mendukung pertumbuhan dan perkembangan yang cepat pada masa bayi dan anak-anak, serta seringnya terkena penyakit infeksi selama awal masa kehidupan. ${ }^{24}$ Kekurangan gizi pada lbu saat hamil dapat mempengaruhi dan menghambat pertumbuhan janin, selain juga dapat menyebabkan adanya gangguan pada fetus, plasenta, dan kesehatan ibu. Beberapa hal ini terutama terjadi di lingkungan masyarakat miskin di mana tidak cukup ketersediaan makanan yang bergizi serta 
pelayanan kesehatan yang tidak memadai untuk Ibu Hamil. 25

Asupan gizi yang baik penting untuk menunjang pertumbuhan anak yang lahir dengan panjang badan lahir pendek agar mendapatkan panjang badan yang normal seiring bertambahnya usia. Hasil penelitian menunjukan bahwa panjang lahir bayi rendah menjadi salah satu faktor risiko kejadian stunting pada balita usia 12 bulan $(O R=16,43$; $\mathrm{p}=0,002){ }^{26}$

Nilai z-skor panjang badan terhadap umur pada bayi baru lahir berkolerasi dengan perkembangan motorik dan sosial emosi sejak bayi berumur nol bulan, yaitu rho $=0,33 ; p=0,004$ untuk motorik dan rho $=0,244$ dengan $p=0,036$ untuk sosial emosi. Sedangkan korelasi terhadap perkembangan bahasa baru tampak pada saat bayi berumur satu bulan yaitu rho $=0,29$ dengan $p=0,031$ dan korelasi terhadap perkembangan kognitif terjadi pada usia dua bulan rho $=0,318$ dengan $p=0,011$. Pada anak lahir stunting median perkembangan bahasa lebih rendah dibandingkan kelompok yang normal. ${ }^{24}$

Oleh karena itu, pencegahan anemia pada ibu hamil dilakukan dengan cara mendeteksi dini untuk mengetahui adanya indikasi anemia gizi besi dengan memeriksakan kadar $\mathrm{Hb}$ dan pemeriksaan kehamilan pada jadwal yang ditentukan oleh petugas kesehatan atau puskesmas. Walaupun seorang ibu tidak memiliki kadar $\mathrm{Hb}$ yang rendah, tetapi ibu hamil diharapkan tetap mengkonsumsi tablet tambah darah yang diberikan sebanyak 90 tablet yang dikonsumsi setiap hari dan dihabiskan kurang lebih 90 hari atau 3 bulan. Hal ini dimaksudkan untuk mencegah terjadi anemia dan penyimpanan cadangan untuk mempersiapkan melahirkan. ${ }^{27}$

\section{SIMPULAN DAN SARAN}

\section{Simpulan}

Kesimpulan yang didapat dari penelitian ini adalah terdapat ibu hamil yang mengalami anemia di Puskesmas Sentolo 1 Kulon Progo yakni sebanyak 30 persen. Sementara kejadian Panjang Badan Lahir Pendek di wilayah kerja Puskesmas Sentolo 1 Kulon Progo sejumlah 20 persen. Untuk karakteristik usia ibu hamil di Puskesmas Sentolo 1 Kulon Progo yaitu 20-25 tahun sebanyak 35 persen, 26 - 30 tahun sebanyak 37 persen, 32 - 35 tahun sebanyak 26 persen, dan 36 - 40 tahun sebanyak 2 persen. Terkati dengan karakteristik pekerjaan ibu hamil di Puskesmas Sentolo 1 Kulon Progo yaitu 24 persen ibu bekerja dan 76 persen ibu tidak bekerja. Karakteristik pendidikan ibu hamil di Puskesmas Sentolo 1 Kulon Progo yaitu 3 persen ibu hamil dengan pendidikan SD, 12 persen ibu hamil berpendidikan SMP, 80 persen ibu hamil dengan pendidikan terakhir SMA, dan 5 persen ibu hamil dengan pendidikan terakhir Perguruan Tinggi.

Berdasarkan temuan statistik tersebut, maka kemudian ditemukan hubungan antara anemia ibu hamil dengan panjang badan lahir pendek di puskesmas Sentolo 1 Kulon Progo ( $p$ value 0,000 ). Ibu hamil yang mengalami anemia 4,13 kali lebih berisiko melahirkan anak dengan panjang badan lahir pendek dari pada ibu yang tidak anemia. Sehingga anemia pada ibu hamil merupakan faktor risiko pada kejadian panjang badan lahir pendek.

\section{Saran}

Untuk penentu kebijakan kesehatan, diharapkan melakukan suplementasi tambah darah dan selalu mengawasi agar tablet benarbenar dikonsumsi oleh ibu hamil untuk mencegah dan memperbaiki kejadian anemia. Sementara bagi praktisi kesehatan diharapkan dapat meningkatkan edukasi gizi melalui progam penyuluhan atau konseling dalam mempersiapkan seorang ibu sebelum kehamilan. Sedangkan bagi ibu hamil sebaiknya memperhatikan asupan makanan dan selalu kontrol kadar Hemoglobin darah agar terhindar dari anemia. Selain itu juga perlu dilakukan intervensi untuk bayi yang lahir pendek agar tetap bisa mengejar pertumbuhan optimal dengan cara pemberian imunisasi, peningkatan pemberian ASI eksklusif, akses makanan yang kaya gizi, serta pemberian mikronutrien seperti suplementasi vitamin A (dalam periode neonatal dan akhir masa kanak-kanak), suplemen zinc, suplemen zat besi. ${ }^{28}$

\section{UCAPAN TERIMAKASIH}

Lembaga Penelitian dan Pengembangan Aisyiyah Pimpinan Wilayah Aisyiyah D.I. Yogyakarta, Dosen dan rekan-rekan sejawat Politeknik Kementerian Kesehatan Yogyakarta, Staf Ahli Gizi Puskesmas Sentolo 1 Kulon 
Progo yang banyak membantu dalam proses pengambilan data penelitian.

\section{RUJUKAN}

1. Uthman, Ed. Understanding Anemia. USA: University Press of Mississippi. 1998.

2. Adriani, M dan Wijatmadi, B. Peranan Gizi dalam Siklus Kehidupan. Jakarta: Kencana Prenada media Group. 2012.

3. WHO. Worldwide Prevalence of Anaemia 2011. Geneva: WHO Press. 2011

4. Riskesdas. Riset Kesehatan Dasar. Jakarta: Badan Penelitian Dan Pengembangan Kesehatan Kementerian Kesehatan RI. 2013

5. Ramakrishnan, Usha. Nutritional Anemias. Washington DC: CRC Press. 2000.

6. Almatsier, Sunita. Gizi Dalam Daur Kehidupan. Jakarta: Gramedia Pustaka Utama. 2011.

7. Barasi, Mary E. At a Glance IImu Gizi. Jakarta: Penerbit Erlangga. 2008.

8. Soeprono, R. Anemia Pada Ibu Hamil. Journal Of Medical Sciences. 1988; 20(4):121-136.

9. Prakash, S dan Yadav, K. Maternal Anemia in Pregnancy: An Overview. International Journal of Pharmacy and Phamateutical Research Human. 2015;4(3):164-179.

10. Manuaba, IBG. Pengantar Kuliah Obstetri. Jakarta : EGC. 2007.

11. Murphy, S. Keguguran : Apa yang Perlu Diketahui. Jakarta: Ardan. 2000.

12. Padila. Buku Ajar Keperawatan Maternitas. Yogyakarta: Nuha Medika. 2014.

13. Dunifon dan Gill. Maternal Employment and Child Well-Being.Cornell University. 2013. http://www.human.cornell.edu/pam/outreac h/parenting/parents/upload/FINALResearch-Brief-Maternal-Employment3.pdf. diunduh pada tanggal 6 Juli 2017

14. Arisman. Gizi Dalam Daur Kehidupan : Buku Ajar Ilmu Gizi, Ed.2. Jakarta: EGC. 2010.
15. Manuaba, IBG.. Konsep Obstetri dan Ginekologi Sosial Indonesia. Jakarta: EGC. 2002.

16. Zimmerman, Woolf, dan Haley. Understanding the Relationship Between Education and Health: A Review of the Evidence and an Examination of Community Perspectives. Agency for Healthcare Research and Quality, Rockville, 2015, MD.http://www.ahrq.gov/professionals/educ ation/curriculum-tools/populationhealth/zimmerman.html diunduh pada tanggal 6 Juli 2017.

17. Huch, Renate dan Schaefer, Roland. Iron deficiency and Iron Deficiency Anemia. Stuttgart-New York: Georg Thieme Verlag. 2006.

18. Supariasa, IDN; Bakri,B dan Fajar, Ibnu. Penilaian Status Gizi. Jakarta: Penerbit Buku Kedokteran EGC. 2012.

19. Suryati. Faktor-faktor yang Mempengaruhi Kejadian BBLR di Wilayah Kerja Puskesmas Air Dingin Tahun 2013. Jurnal Kesehatan Masyarakat Andalas. 2013;8(2):72-78

20. Soetjiningsih dan Ranuh, Gde. Tumbuh Kembang Anak: Edisi 2. Jakarta: EGC. 2013.

21. Gaur, S; Kataria,S.K; dan Agarwal, Ritu. A Study of Effects of Maternal Anaemia on Anthropometric Measurements of Newborns. The Pharma Innovation Journal. 2015;4(8):69-71.

22. Grober, Uwe. Mikronutrien: Penyelarasan Metabolik, Pencegahan, dan Terapi. Jakarta: EGC. 2012.

23. Ibanez, G.B; Sanchez, A.S; Penafiel, C.O.R. "Iron Defisiency Anemia". Revista Medica del Hospital General Mexico. 2015; 79(2):88-97.

24. Ernawati,F; Muljati,S; S.Dewi Made; dan Safitri,A. Hubungan Panjang Badan Lahir tehadap Perkembangan Anak Usia 12 Bulan. Jurnal Penel Gizi Makan. 2014;37(2):109-118

25. Istiany dan Rusilanti. Gizi Terapan. Bandung: PT Remaja Rosdakarya. 2013. 
26. Meilyasari, F; Isnawati, M. Faktor Resiko Kejadian Stunting pada Balita Usia 12 Bulan di Desa Purwokerto Kecamatan Patebon, Kabupaten Kendal. Journal of Nutrition College. 2014; 3(2): 16-25.

27. Purnadhibrata, I.M. Upaya Pencegahan Anemia Gizi Pada Ibu Hamil. Jurnal IImu Gizi. 2011;2(2):118-124.
28. Mitra. Permasalahan Anak Pendek (Stunting) dan Intervensi untuk Mencegah Terjadinya Stunting (Suatu Kajian Kepustakaan). Jurnal Kesehatan Komunitas. 2015;2(6): 254-261. 